\title{
Recombinant anthrax lethal toxin inhibits cell motility and invasion in breast cancer cells through the dysregulation of Rho GTPases
}

\author{
DANA EL-CHAMI, MARIA AL HADDAD, RALPH ABI-HABIB and MIRVAT EL-SIBAI
}

\author{
Department of Natural Sciences, School of Arts and Sciences, Lebanese American University, Beirut 1102 2801, Lebanon
}

Received August 17, 2020; Accepted November 27, 2020

DOI: $10.3892 / \mathrm{ol} .2020 .12424$

\begin{abstract}
Breast cancer is the leading cause of cancerassociated death among women worldwide. Targeting breast cancer cell metastasis is an important therapeutic approach. The MAPK pathway is a key cell signaling pathway that plays a pivotal role in cellular invasion and migration. Numerous studies have identified the MAPK pathway as a way to target cell survival and motility. The present study treated MBA-MD-231 breast cancer cells with anthrax lethal toxin (LeTx), a potent MAPK inhibitor that selectively cleaves and inactivates all MEKs, as a potential therapeutic method to inhibit breast cancer cell migration. LeTx has been demonstrated to affect breast cancer cell migration. Cells treated with LeTx showed a significant decrease in motility, as observed using wound healing and random $2 \mathrm{D}$ motility assays. Additionally, cells treated with LeTx showed an increase in adhesion, which would explain the decrease in migration. Pull-down assays examining the activation status of the members of the Rho family of GTPases revealed an increase in RhoA activation accompanied by a decrease in $\mathrm{Cdc} 42$ activation following LeTx treatment. Finally, LeTx mediated a decrease in invasion using a Boyden chamber assay, which could be a result of the decrease in Cdc42 activation. The present study reported the effect of LeTx treatment on the migration, adhesion and invasion of breast cancer cells, demonstrating that this effect was associated with the dysregulation of the Rho GTPases, RhoA and Cdc42.
\end{abstract}

\section{Introduction}

Breast cancer is the most common cancer diagnosed among women in the US and the second leading cause of cancer death among women around the world (1). Breast tumors are heterogenous, exhibiting notable phenotypic diversity.

Correspondence to: Dr Mirvat El-Sibai, Department of Natural Sciences, School of Arts and Sciences, Lebanese American University, P.O. Box 13-5053, Chouran, Beirut 1102 2801, Lebanon E-mail: mirvat.elsibai@lau.edu.lb

Key words: breast cancer, invasion, anthrax lethal toxin, MAPK, migration, Rho GTPases
Through molecular analysis and gene profiling, breast tumors are subclassified into three types: HER2 Positive, estrogen receptor (ER) positive and basal-like breast cancer (2).

HER2, encoded by the ERBB2 gene, is a member of the human epidermal growth factor receptor family of proteins (3). HER2, a receptor tyrosine kinase, regulates internal cell activities such as cell proliferation and survival (4). When HER2 is overexpressed, it leads to the overactivation of cellular pathways such as the PI3K and the MAPK pathways, which are known to be involved in tumorigenesis (5). As for the estrogen receptor, once activated, it functions as a transcription factor leading to the transcription of a number of genes involved in cell proliferation and survival, including c-fos, insulin-like growth factor binding protein 4 and E2F1 (6). Lastly, progesterone increases breast cell proliferation through the activation of the DNA replication machinery (7). All of these characteristics have led to the high occurrence of aggressive, invasive and metastatic profiles of breast cancer, with limited targeted therapeutic options (8).

Cellular motility is a structured process involved in inflammation, embryogenesis, migration and invasion of cells (9). Being a vital process, cell motility is tightly regulated by several proteins, including the Rho family of small GTPases. These consist of 22 members grouped into subfamilies according to their sequence homology $(10,11)$. Rho GTPases are molecular switches that play an important role in regulating the dynamics of the actin cytoskeleton, impacting cellular polarity, adhesion and invasion $(12,13)$.

Rho GTPases switch between an active GTP-bound form and an inactive GDP-bound form. This is regulated by upstream effectors such as guanine exchange factors (GEFs) and GTPase activating proteins (GAPs). GEFs are nucleotide exchange factors that catalyze the dissociation of GDP and its exchange to GTP, leading to the activation of the Rho GTPase. GAPs are GTPase-activating proteins, which activate the intrinsic GTPase activity of the Rho GTPase, leading to the inactivation of the protein $(14,15)$.

The MAPK family of proteins includes three kinase types: Extracellular regulated kinases (ERKs), the stress-activated protein kinases p38 and JNKs (16). The Raf/MEK/ERK pathway is a signal transduction pathway that relays signals from cell surface receptors to transcription factors, therefore regulating gene expression. After activation, the small GTPase Ras recruits and phosphorylates Raf (MAP3K) (17). 
Successively, Raf phosphorylates a second kinase, MEK (MAP2K), which then phosphorylates two proteins, ERK1 and ERK2; after phosphorylation, ERK1/2 are translocated to the nucleus, where they phosphorylate different transcription factors, altering gene expression (17). The translocation of ERK into the nucleus affects numerous cell processes, such as proliferation, cell cycle progression, adhesion, invasion, survival, metabolism and differentiation (17). The most notable targets of ERK1/2 are c-Myc, c-Fos, Elk1 and c-Jun $(16,17)$.

Anthrax lethal toxin (LeTx) is a binary toxin produced by the Gram-positive bacteria, Bacillus anthracis (18). B. anthracis contains two virulence encoding plasmids: pXO1 And pXO2. PXO1 encodes for three factors: Protective agent (PA), lethal factor (LF) and edema factor. Although separately non-toxic, a combination of PA and LF generates LeTx (19). PA $(83 \mathrm{kDa})$ binds to the host cell surface receptors, tumor endothelial marker 8 (TEM8) or capillary morphogenesis gene 2 (CMG2), with TEM8 demonstrating increased expression in breast tumor tissue $(18,19)$. Upon binding to TEM8 or CMG2, PA is cleaved by furin-like proteases, releasing a $20 \mathrm{kDa}$ amino-terminal fragment and yielding a 63-kDa active PA fragment (PA63) $(18,19)$. PA63 then oligomerizes, forming a ring-shaped, pre-pore heptameric or octameric structure (18). The formation of the PA63 pre-pore complex allows the binding of three to four LF molecules, depending on whether the PA63 pre-pore complex is in the heptameric or octameric form, respectively $(18,19)$. Binding of LF initiates internalization of the complex into the cell through receptor-mediated endocytosis; upon acidification of the endosome, PA63 undergoes a conformational change into a mature pore complex that subsequently translocates LF into the cytosol (18-20). LF is a matrix metalloproteinase that cleaves and inactivates all MEKs, thus inhibiting all three branches of the MAPK pathway (20).

Previous studies have investigated LeTx as a potential therapeutic target and abundant literature exists describing the selective antitumor potential of LeTx in a number of tumor types, including melanoma and acute myeloid leukemia, both in vitro and in vivo (21-26). The tumor selectivity of LeTx derives from the fact that the majority of normal cells, with the exception of endothelial cells and macrophages, are not sensitive to the inhibition of the MAPK pathway (25). Hence, this pathway is not essential for the survival of the majority of normal cells. Moreover, not all cancer cells are sensitive to the inhibition of the MAPK pathways. For example, several studies have shown that melanoma cells that carry N-Ras mutations are not sensitive to the LF-mediated inhibition of the MAPK pathway, while those carrying a V600E B-Raf mutation are sensitive to the inhibition of this pathway $(25,27)$. Previously, it was also demonstrated that LeTx successfully decreased cellular motility and invasion of glioblastoma cells by increasing their adhesion via an increase in RhoA activity (28).

The aim of the present study was to investigate the effect of LeTx, a MEK inhibitor, on breast cancer cell motility and invasion. First, the effect of LeTx on the MAPK pathway was examined through analyzing the phosphorylation status of ERK. Furthermore, the effect of LeTx on the migration, adhesion and invasion of MDA-MB-231, a highly aggressive and invasive type of breast cancer cell line, was studied.

\section{Materials and methods}

Cell culture. The human epithelial triple negative breast cancer cell line MDA-MB-231 was cultured adherently in Dulbecco's modified Eagle's medium (DMEM) supplemented with $10 \%$ fetal bovine serum (FBS) and 100 units penicillin/streptomycin (all Invitrogen; Thermo Fisher Scientific, Inc.) at $37^{\circ} \mathrm{C}$ and $5 \% \mathrm{CO}_{2}$ in a humidified chamber.

Drug concentrations. We have previously shown that the MDA-MB-231 cell line was not sensitive to LeTx, hence its viability and proliferation were not affected by the maximum LeTx concentration used in the present assay (Abi-Habib et al, unpublished data). Therefore, a concentration of LeTx consisting of $10^{-8} \mathrm{M}$ PA and $10^{-9} \mathrm{M}$ LF was used for cell treatment for $24 \mathrm{~h}$. Cells were also treated with the MEK1/2 inhibitor U0126 (Sigma-Aldrich; Merck KGaA) at a final concentration of $50 \mu \mathrm{M}$ for $24 \mathrm{~h}$.

Pull-down assay. Cell lysates were collected from breast cancer cells following treatment with LeTx $\left(10^{-8} \mathrm{M}\right.$ PA $\left./ 10^{-9} \mathrm{M} \mathrm{LF}\right)$ or $\mathrm{U} 0126(50 \mu \mathrm{M})$ for $24 \mathrm{~h}$. The RhoA/Rac1/Cdc42 Activation Assay Combo kit (cat. no. STA-405; Cell Biolabs, Inc.) was used for a pull-down assay following the manufacturer's instructions. Briefly, the cells were lysed with lysis buffer (25 mM HEPES, 1\% Igepal, $150 \mathrm{mM} \mathrm{NaCl}, 10 \mathrm{mM} \mathrm{MgCl}_{2}$, $10 \%$ glycerol, 1 mM EDTA, $1 \mathrm{mM} \mathrm{NaVO}_{4}, 20 \mathrm{mM} \mathrm{NaF}, 1 \mathrm{mM}$ PMSF, $100 \mathrm{lg} / \mathrm{ml}$ aprotinin and $5 \mathrm{lM}$ leupeptin). Lysates were cleared by centrifugation for $1 \mathrm{~min}$ at $1,500 \mathrm{xg}$ at $4^{\circ} \mathrm{C}$ and incubated with GST-RBD beads $(20 \mu \mathrm{g})$ or GST-CRIB beads $(20 \mu \mathrm{g})$ provided in the aforementioned kit for $1 \mathrm{~h}$ at $4^{\circ} \mathrm{C}$ with gentle shaking. Then, samples were centrifuged for $2 \mathrm{~min}$ at $1,000 \times \mathrm{g}$ at $4^{\circ} \mathrm{C}$, and the pellet was washed 3 times with PBS. Beads alone samples (without cell lysate) were used as a negative control and the total cell lysate (before incubation with the beads) were blotted for total RhoA, Cdc42 and $\beta$-actin.

Western blotting. Proteins were extracted using the $1 \mathrm{X}$ lysis buffer (25 mM HEPES, $1 \%$ Igepal, $150 \mathrm{mM} \mathrm{NaCl}$, $10 \mathrm{mM} \mathrm{MgCl}_{2}, 10 \%$ glycerol, $1 \mathrm{mM}$ EDTA, $1 \mathrm{mM} \mathrm{NaVO}_{4}$, $20 \mathrm{mM} \mathrm{NaF}, 1 \mathrm{mM}$ PMSF, $100 \mathrm{lg} / \mathrm{ml}$ aprotinin and $5 \mathrm{lM}$ leupeptin). Protein concentrations were determined using the Bradford assay (Bio-Rad Laboratories, Inc.). Proteins $(25 \mu \mathrm{g} / \mathrm{ml})$ were separated by $9 \%$ SDS-PAGE and transferred onto PVDF membranes. Membranes were blocked with 5\% BSA (Sigma-Aldrich; Merck KGaA) in PBS for $1 \mathrm{~h}$ at room temperature and then incubated with the corresponding primary antibodies overnight at $4^{\circ} \mathrm{C}$ and HRP-conjugated secondary antibodies for $1 \mathrm{~h}$ at room temperature the following day. GTP-RhoA and GTP-Cdc42 were detected using anti-RhoA (1:500) or anti-Cdc42 (1:500), provided in the aforementioned RhoA/Rac1/Cdc42 Activation Assay Combo kit. Mouse monoclonal anti-ERK (1:200; cat. no. ab54230), mouse monoclonal anti-phospho-Erk1 (pT202/pY204) + phospho-Erk2 (pT185/pY187) (1:200; cat. no. ab50011) and rabbit polyclonal anti- $\beta$-actin antibodies (1:500; cat. no. ab8227) were purchased from Abcam. Anti-rabbit (cat. no. W4011) and anti-mouse (cat. no. W4021) HRP-conjugated secondary antibodies (both 1:1,000) were obtained from Promega Corporation. Finally, the bands were visualized with chemiluminescent reagent ECL 
(GE Healthcare Life Sciences) using the Chemidoc imaging system (Bio-Rad Laboratories, Inc.). The protein expression levels were compared by densitometry using ImageJ v1.51k (National Institutes of Health) (29).

Wound healing. Cells were cultured to confluence on culture plates. After $24 \mathrm{~h}$, a wound was made in the monolayer with a sterile pipette tip. Cells were then washed twice with PBS to remove debris and new medium was added. Images were captured at 0 and $72 \mathrm{~h}$. Wound widths were measured at 13 different points for each wound, and the average rate of wound closure was calculated (in $\mu \mathrm{m} / \mathrm{h}$ ) using ImageJ (29). The assay was done using infinity-corrected optics on a Zeiss Observer Z1 microscope supplemented with a computer-driven Roper cooled CCD camera and operated by Zen Blue 2.5 software (all Zeiss AG).

Random cell motility assay (time-lapse). Cells treated as indicated were imaged randomly moving in DMEM (with 10\% FBS and 1\% Penicillin/Streptomycin) in their respective plates that were placed on a heated stage $\left(37^{\circ} \mathrm{C}\right)$ with controlled $\mathrm{CO}_{2}$ levels (5\%). Cell images were collected every min for $2 \mathrm{~h}$ using a 20x objective lens on the Zeiss Observer Z1 microscope. The total distance traveled by the cells was quantified using the ROI tracker plugin in ImageJ (29). The rate $(\mu \mathrm{m} / \mathrm{min})$ of at least 10 randomly selected cells per condition was then calculated by dividing the total distance traveled over time. Finally, the difference in cell motility was also expressed as fold change of the treated cells normalized to the control (29).

Adhesion assay. Collagen Solution, Type I (Sigma-Aldrich; Merck KGaA) was used to coat 96-well plates overnight at $37^{\circ} \mathrm{C}$ then washed with washing buffer (0.1\% BSA in RPMI-1620 AQ media). The plates were then blocked with $0.5 \%$ BSA in RPMI-1620 AQ media at $37^{\circ} \mathrm{C}$ in a $\mathrm{CO}_{2}$ incubator for $1 \mathrm{~h}$. This was followed by washing the plates and chilling them on ice. Meanwhile, the cells were trypsinized and counted to $4 \times 10^{5}$ cells $/ \mathrm{ml}$. In total, $50 \mu \mathrm{l}$ of cells were added in each well and incubated at $37^{\circ} \mathrm{C}$ in a $\mathrm{CO}_{2}$ incubator for $30 \mathrm{~min}$. The plates were then shaken and washed three times with PBS Cells were then fixed with $4 \%$ paraformaldehyde at room temperature for $10 \mathrm{~min}$, washed and stained with crystal violet $(5 \mathrm{mg} / \mathrm{ml}$ in $2 \%$ ethanol) for $10 \mathrm{~min}$ at room temperature. Following the staining, the plates were washed extensively with water and left to dry completely. Crystal violet was solubilized by incubating the cells with $2 \%$ SDS for $30 \mathrm{~min}$ at room temperature. The absorption of the plates was read at $550 \mathrm{~nm}$ using a Varioskan Flash Multimode reader (Thermo Fisher Scientific, Inc.).

Invasion assay. Cells were treated with LeTx or left untreated as control, and the invasion assay was performed following the treatment period using the collagen-based invasion assay kit (cat. no. ECM551; EMD Millipore) according to the manufacturer's instructions. Briefly, $24 \mathrm{~h}$ prior to the assay, cells were starved with serum-free medium. Cells were harvested, centrifuged at $600 \mathrm{x}$ g for $5 \mathrm{~min}$ at $4{ }^{\circ} \mathrm{C}$ and then resuspended in quenching medium (without serum). Cells were then counted using a hemocytometer and brought to a concentration of $1 \times 10^{6}$ cells $/ \mathrm{ml}$. In the meantime, the kit inserts (collagen-coated $8-\mu \mathrm{m}$ pore size polycarbonate membrane) were rehydrated
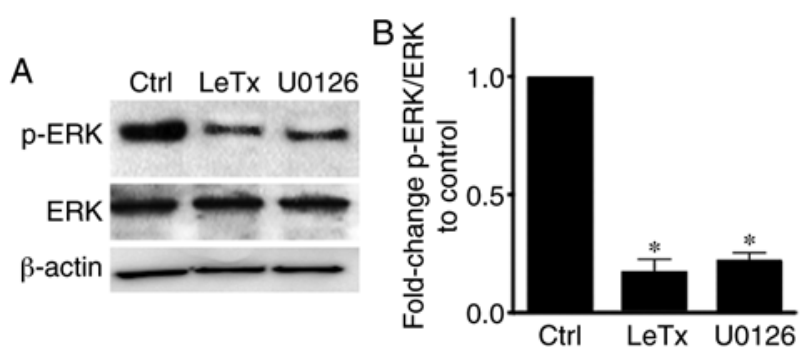

Figure 1. LeTx treatment leads to a decrease in p-ERK in breast cancer cells (A) MDA-MB-231 cells were either treated with recombinant LeTx or U0126 for $24 \mathrm{~h}$. Cells were lysed and western blot was conducted using p-ERK, ERK or $\beta$-actin antibodies. (B) Level of expression were quantified using ImageJ and represented by fold-change. ${ }^{*} \mathrm{P}<0.05$ vs. Ctrl. LeTx, anthrax lethal toxin; p-, phosphorylated; Ctrl, control.

with prewarmed $300 \mu 1$ of serum-free medium for $30 \mathrm{~min}$ at room temperature. After rehydration, $250 \mu \mathrm{l}$ of medium was removed from the inserts, and $250 \mu \mathrm{l}$ of cell suspension was added. Inserts were then placed in a 24 -well plate, and $500 \mu \mathrm{l}$ of complete medium (with $10 \%$ serum) was added to the lower wells. Plates were incubated for $48 \mathrm{~h}$ at $37^{\circ} \mathrm{C}$ in a $\mathrm{CO}_{2}$ incubator. Following the incubation period, inserts were stained for $20 \mathrm{~min}$ at room temperature with $400 \mu \mathrm{l}$ of cell stain provided with the kit. The stain was then extracted with extraction buffer (also provided). The extracted stain $(100 \mu \mathrm{l})$ was then transferred to a 96-well plate suitable for colorimetric measurement using a plate reader. Optical density was then measured at $560 \mathrm{~nm}$.

Statistical analysis. The results reported represent mean values from three independent experiments. The error estimates are given as \pm SEM. The P-values were calculated by a one-way ANOVA or unpaired t-test. Tukey's post hoc test was used for comparing all possible group pairings to check if the changes observed in the results were significant. $\mathrm{P}<0.05$ was considered to indicate a statistically significant difference.

\section{Results}

LeTx treatment leads to a decrease in phosphorylated ( $p$-)ERK in breast cancer cells. In the ERK MAPK module, MEK1/2 (a MAPK kinase) phosphorylates and subsequently activates ERK (a MAP kinase) $(20,21)$. LeTx is known to cleave MEK by degrading it in order to inhibit the MAPK pathway in cells (26). The present results showed a decrease in the level of p-ERK upon treatment of MBA-MD-231 cells with LeTx and the MEK1/2 inhibitor U0126 in comparison with control, while leaving the total ERK expression intact (Fig. 1).

LeTx treatment leads to a decrease in migration in breast cancer cells. In order to study the effect of LeTx on MDA-MB-231 cell migration, a 2D wound closure assay was performed. The rate of wound closure was calculated over the span of $72 \mathrm{~h}$. Treatment with LeTx caused a decrease in the rate of wound closure from 3.8 to $0.9 \mu \mathrm{m} / \mathrm{h}(\sim 2.4$-fold decrease in wound closure rate) (Fig. 2A and B).

In order to eliminate the confounding effect of cell proliferation, a time lapse examination of individual cells undergoing random migration in serum was also performed (29). 
A
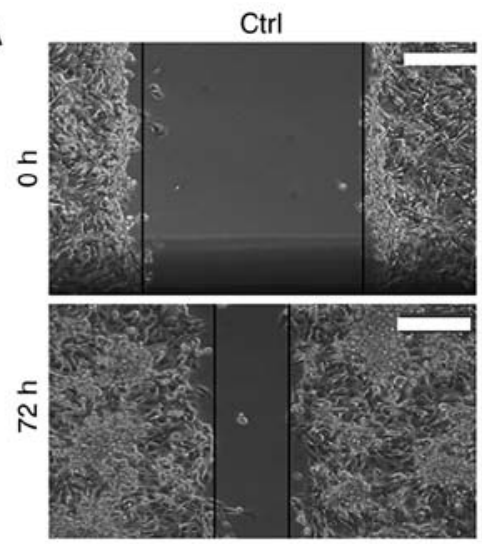

LeTx
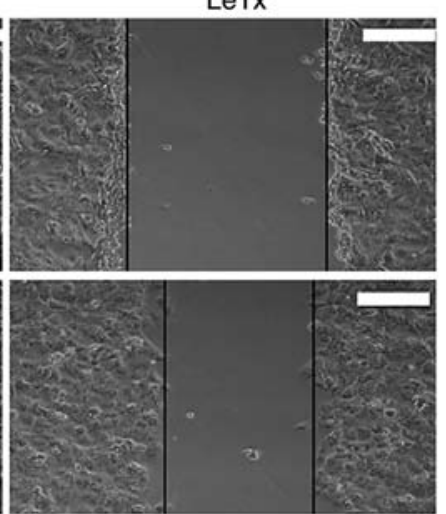

B

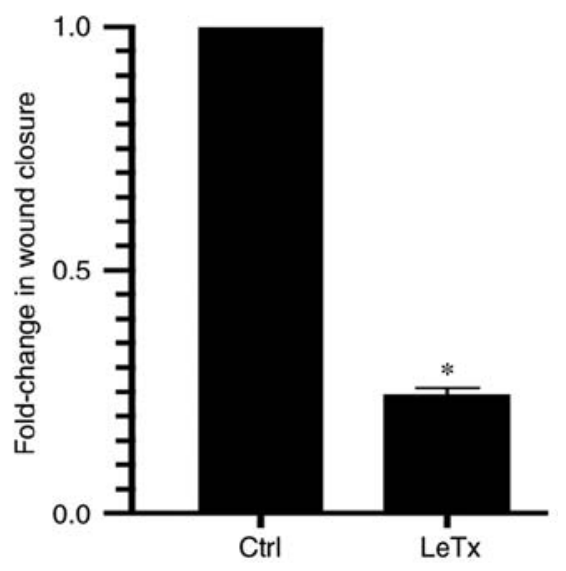

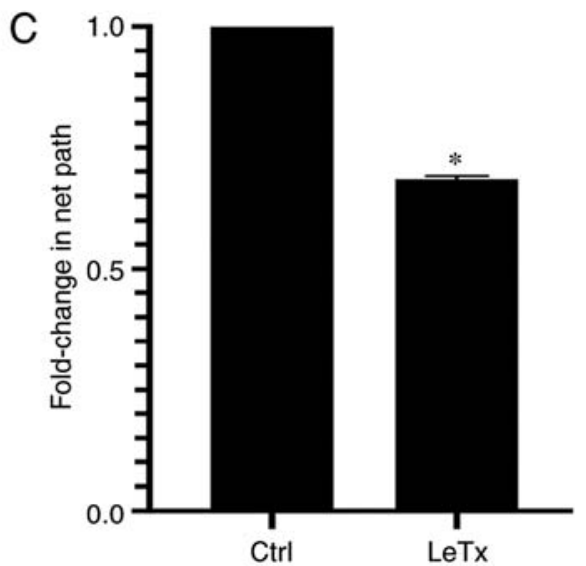

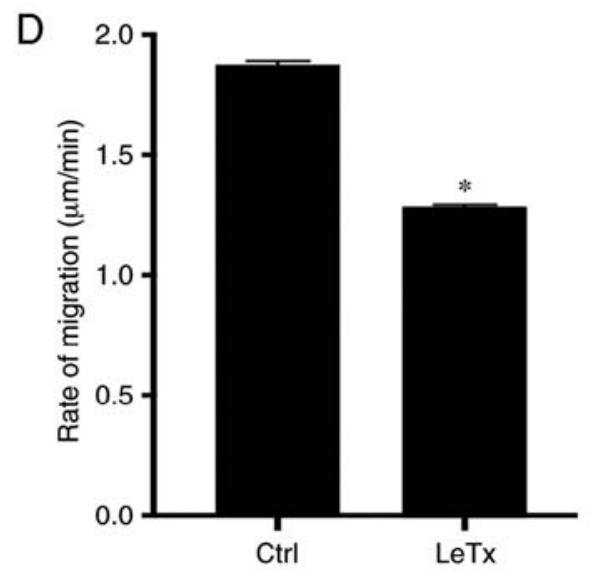

Figure 2. LeTx treatment leads to a decrease in migration in breast cancer cells. Monolayers of cells were wounded and images were captured at 0 and $72 \mathrm{~h}$. (A) Representative wound closure images. Scale bar, $100 \mu \mathrm{m}$. (B) Frames were quantitated using ImageJ. (C) Random 2D migration quantitation showing net path of LeTx treated cells and control cells represented. (D) Rate of migration of treated cells in comparison with Ctrl cells. * $\mathrm{P}<0.05$ vs. Ctrl. LeTx, anthrax lethal toxin; Ctrl, control.

Consistently with the results obtained in the wound healing, a 0.75 -fold decrease in the net path and rate of migration was observed in cells treated with LeTx (Fig. 2C and D; Videos S1 and S2).

\section{LeTx treatment leads to an increase in adhesion in breast} cancer cells. Since treated cells exhibited a reduction in total net path and rate of migration, it was hypothesized that this reduction in migration may be due to an increase in MDA-MB-231 adhesion to the underlying matrix, as previously seen in another tumor model (28). Indeed, cells treated with LeTx displayed a $~ 0.7$-fold increase in adhesion (Fig. 3).

\section{LeTx treatment leads to an alteration of Rho GTPase activation.} Since LeTx-treated MBA-MD-231 cells exhibited an increase in cell adhesion, it was analyzed whether this was due to an increase in RhoA activation. RhoA at the leading edge of cells is needed for the maturation of the focal adhesions that anchor the cell to the underlying extracellular matrix (29). Performing a pull-down assay, using GST-RBD and GST-PAK beads, revealed an increase in RhoA activation in the LeTX-treated cells, which is consistent with the increase in total adhesion (Fig. 4A). In addition, there was a decrease in Cdc42 activation, which might additionally explain the decrease in cell migration in response to LeTx treatment (Fig. 4B).

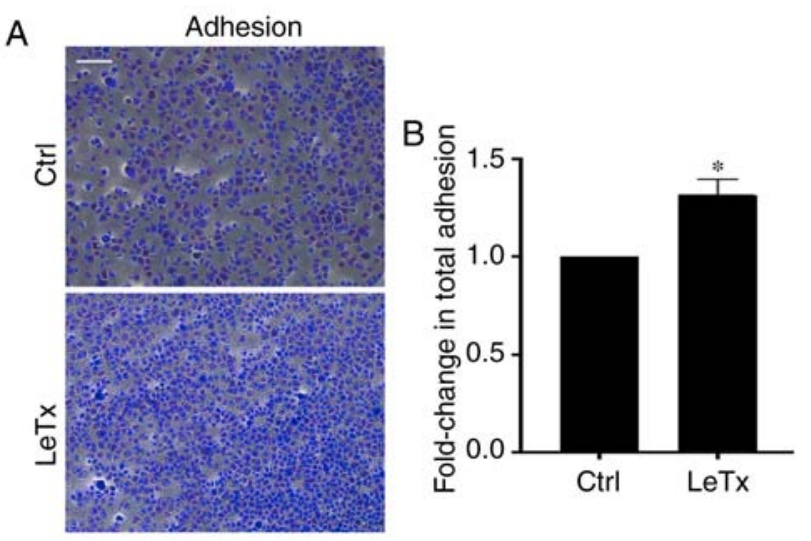

Figure 3. LeTx treatment leads to an increase in adhesion in breast cancer cells. (A) Representative micrographs of LeTx treated cells and control cells. Scale, $100 \mu \mathrm{m}$. (B) Quantitation of adhesion changes. ${ }^{*} \mathrm{P}<0.05$ vs. Ctrl. LeTx, anthrax lethal toxin; Ctrl, control.

LeTx treatment leads to a decrease in breast cancer invasion. $\mathrm{Cdc} 42$ is a potent regulator of invadopodia and cancer cell invasion (30). Accordingly, having detected an inhibition of $\mathrm{Cdc} 42$ in response to LeTx treatment in these cells, a decrease in invasion was expected. Indeed, the results showed a decrease in invasion upon treating cells with LeTx (Fig. 5A and B). 
A

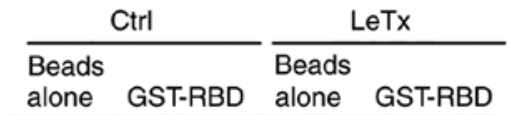

alone GST-RBD alone GSTRBD
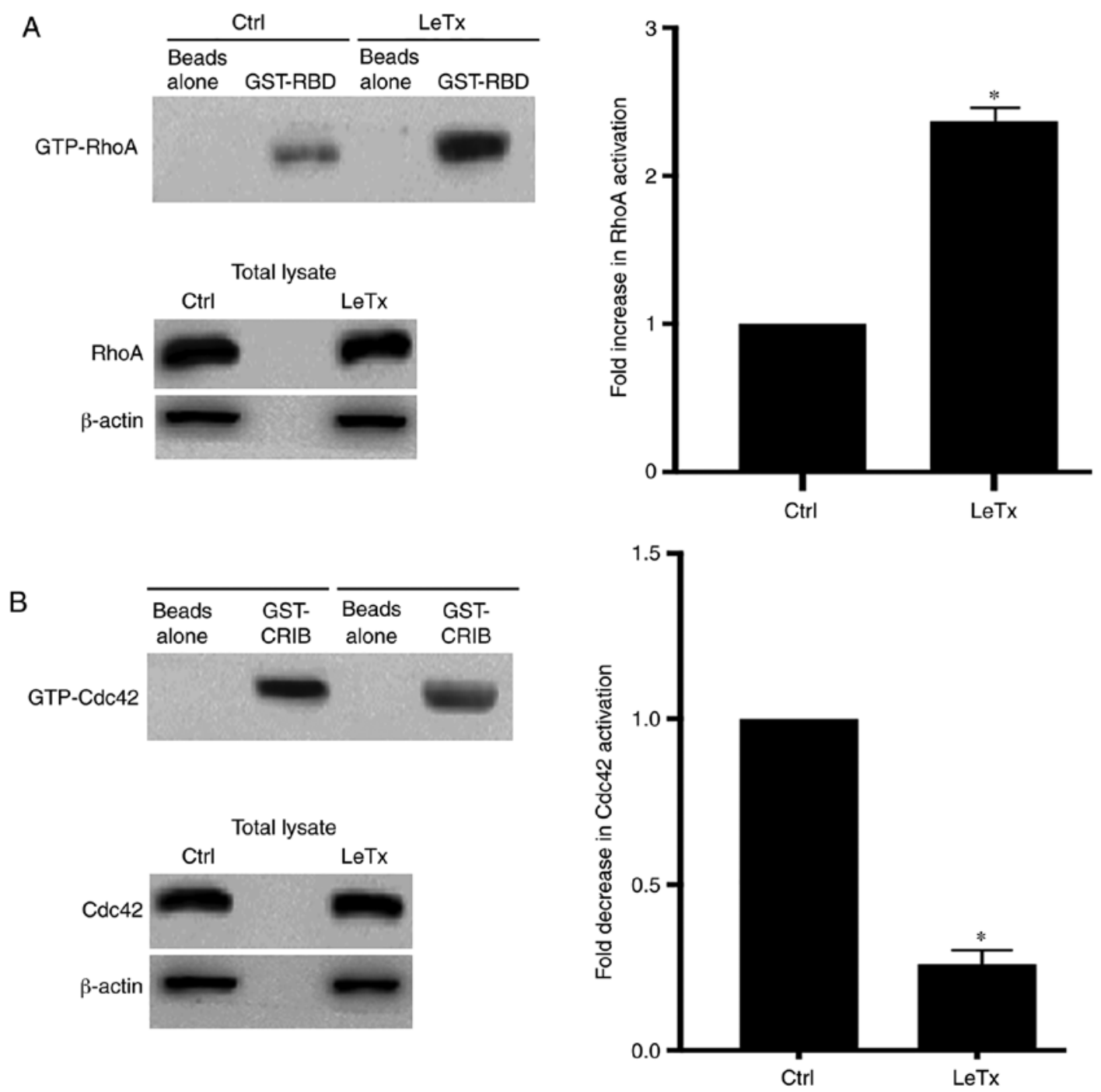

Figure 4. LeTx treatment leads to an alteration of Rho GTPase activation. (A) Pull-down assay of active RhoA. Samples were immunoblotted with RhoA or $\beta$-actin antibodies. Graphs show quantitation of the gels using the ImageJ software. Bands of active RhoA were normalized to the amount of total proteins. (B) Pull-down assay of active Cdc42. Samples were immunoblotted with Cdc42 or $\beta$-actin antibodies. Graphs show quantitation of the gels using the Image J software. Bands of active Cdc42 were normalized to the amount of total proteins. ${ }^{*} \mathrm{P}<0.05$ vs. Ctrl. LeTx, anthrax lethal toxin; Ctrl, control.

Collectively, these results consolidated LeTx as a potential potent therapeutic agent to target breast cancer migration and invasion through the inhibition of cell migration regulators.

\section{Discussion}

Metastatic lesions attack vital organs leading to a poor prognosis of patients with breast cancer (31). The MAPK pathway has been described to play a vital role in cellular proliferation, survival and migration. ERK, a member of the MAPK cascade has been shown to lead to an increased cell proliferation upon overactivation in a number of different cancer types, including pancreatic cancer, colon cancer, melanoma and breast cancer $(32,33)$. Previous studies have established that inactivation of the MAPK pathway could lead to the inhibition of cancer cell survival as well as the inhibition of migration and invasion $(28,34)$.

LeTx is a binary toxin composed of two proteins: PA And LF. LF is a zinc-activated metalloprotease that inhibits the MAPK pathway by cleaving MEKs $(35,36)$. Based on the
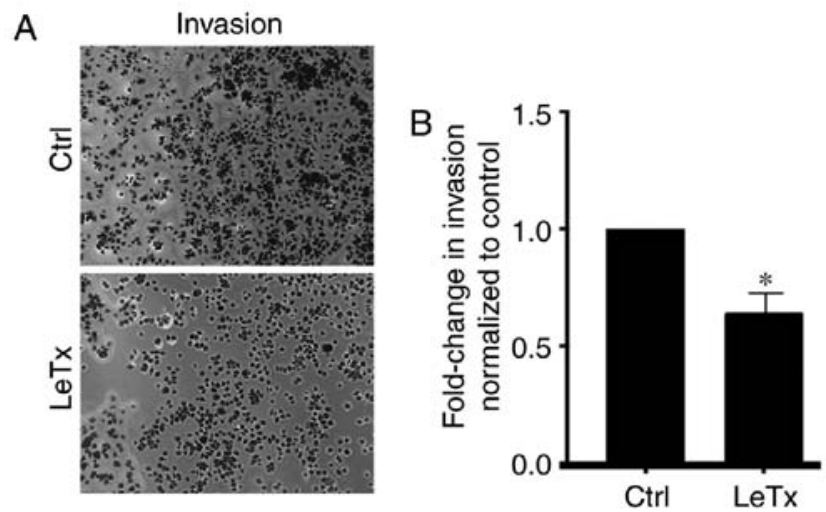

Figure 5. LeTx treatment leads to a decrease in breast cancer invasion and invadopodia formation through $\mathrm{Cdc} 42$ inhibition. (A) Cells were treated with LeTx or untreated. (B) Quantified invasion data. ${ }^{*} \mathrm{P}<0.05$ vs. Ctrl. LeTx, anthrax lethal toxin; Ctrl, control.

ability of LeTx to cause cell death or inhibition of migration and invasion due to MAPK inhibition, breast cancer cells were 
treated with LeTx, and the migratory and invasive capabilities of the cells were examined in the present study.

Previous research has shown the ability of LeTx to impair migration of cells and disrupt their polarity (37). The present study treated breast cancer cells with LeTx, which led to a decrease in 2D cell motility as shown in the quantification of the wound healing assay. Consequently, it was suspected that there was a relationship between LeTx and an increase in cellular adhesion resulting in a decreased net path and rate of migration. After treatment with the toxin, cells exhibited an increase in adhesion as shown in the adhesion assay. We have previously shown that overexpression of RhoA leads to an increase in cell adhesion in breast cancer cells, among other tumor types $(28,29,38-41)$. RhoA regulates focal adhesion dynamics via its downstream effector Rho-associated protein kinase 1 and the formation of stress fibers needed for migration (28,38-41). At focal contact points with the underlying extracellular matrix, cells recruit RhoA, which in turn recruits actin to form premature adhesions $(28,40-43)$. RhoA activity then mediates the maturation of these contacts into mature adhesions (40). In parallel, as previously mentioned, ERK, through Fos-related antigen 1, leads to the inhibition of RhoA $(31,42)$. Thus, the disruption of the inhibition of the MAPK pathway via LeTx should relieve inhibition of RhoA activation. The current study reported that, indeed, the increased adhesion phenotype was due to an increase in RhoA activation upon LeTx treatment, in addition to a decrease in Cdc42 activation, which might be the mechanism behind the decrease in cell migration.

Lastly, the present study explored the effect of LeTx on invasion of MDA-MB-231 cells. Treating the cells with LeTx led to a decrease in invasion. Cdc42 is known to play a role in invasion of cells by contributing to the formation of invadopodia by activating actin-related protein $2 / 3$ via Neural Wiskott-Aldrich syndrome protein and by exerting an effect on matrix metalloproteinases, which is necessary for their translocation to invadopodia $(43,44)$. Having observed decreased Cdc42 activation in treated cells in pull-down assays, it was hypothesized that the effect exerted by LeTx on invasion was through Cdc42.

Overall, the present study has demonstrated the effect of LeTx on the migration and invasive capabilities of breast cancer cells via the MAPK pathway. By inhibiting MAPK, cells demonstrated decreased motility, increased adhesion and decreased invasion, which are characteristics attributed to cancer metastasis (45). The current data has been indicative of the importance of Rho GTPases in these cellular processes and offers an insight on the potential use of LeTx in therapeutic approaches for breast cancer. Although few studies have linked Rho GTPases and the MAPK pathway $(46,47)$, the exact mechanism involved and the crosstalk between these requires further investigation. Future studies should investigate the effectiveness of LeTx treatment on the inhibition of metastasis in vivo.

\section{Acknowledgements}

The authors would like to thank Dr Isabelle Fakhoury (Department of Natural Sciences, School of Arts and Sciences, Lebanese American University, Beirut, Lebanon) for help with the experiments.

\section{Funding}

The present study was supported by intramural funding at the Lebanese American University.

\section{Availability of data and materials}

The datasets used and/or analyzed during the current study are available from the corresponding author on reasonable request.

\section{Authors' contributions}

DEC and MAH performed the experiments and analyzed the data. RAH and MES are the principal investigators on the project who designed and supervised the project, wrote the manuscript and provided the resources. All authors read and approved the final manuscript.

\section{Ethics approval and consent to participate}

Not applicable.

\section{Patient consent for publication}

Not applicable.

\section{Competing interests}

The authors declare that they have no competing interests.

\section{References}

1. DeSantis CE, Fedewa SA, Goding Sauer A, Kramer JL, Smith RA and Jemal A: Breast cancer statistics, 2015: Convergence of incidence rates between black and white women. CA Cancer J Clin 66: 31-42, 2016

2. Perou CM, Sørlie T, Eisen MB, van de Rijn M, Jeffrey SS, Rees CA, Pollack JR, Ross DT, Johnsen H, Akslen LA, et al: Molecular portraits of human breast tumours. Nature 406: 747-752, 2000.

3. Callahan R and Hurvitz S: Human epidermal growth factor receptor-2-positive breast cancer: Current management of early, advanced, and recurrent disease. Curr Opin Obstet Gynecol 23: 37-43, 2011.

4. Sauter G, Lee J, Bartlett JMS, Slamon DJ and Press MF: Guidelines for human epidermal growth factor receptor 2 testing: Biologic and methodologic considerations. J Clin Oncol 27: 1323-1333, 2009.

5. Hoeferlin LA, E Chalfant $\mathrm{C}$ and Park MA: Challenges in the treatment of triple negative and HER2-overexpressing breast cancer. J Surg Sci 1: 3-7, 2013.

6. Fragomeni SM, Sciallis A and Jeruss JS: Molecular subtypes and local-regional control of breast cancer. Surg Oncol Clin N Am 27: 95-120, 2018.

7. Daniel AR, Hagan CR and Lange CA: Progesterone receptor action: Defining a role in breast cancer. Expert Rev Endocrinol Metab 6: 359-369, 2011

8. Toft DJ and Cryns VL: Minireview: Basal-Like breast cancer: From molecular profiles to targeted therapies. Mol Endocrinol 25: 199-211, 2011.

9. Hanna S and El-Sibai M: Signaling networks of Rho GTPases in cell motility. Cell Signal 25: 1955-1961, 2013.

10. Zandvakili I, Lin Y, Morris JC and Zheng Y: Rho GTPases: Antior pro-neoplastic targets? Oncogene 36: 3213-3222, 2017.

11. Al-Koussa H, Atat OE, Jaafar L, Tashjian H and El-Sibai M: The role of Rho GTPases in motility and invasion of glioblastoma cells. Anal Cell Pathol (Amst) 2020: 9274016, 2020.

12. Etienne-Manneville $S$ and Hall A: Rho GTPases in cell biology. Nature 420: 629-635, 2002. 
13. Zgheib P, Daher CF, Mroueh M, Nasrallah A, Taleb RI and El-Sibai M: Daucus carota pentane/diethyl ether fraction inhibits motility and reduces invasion of cancer cells. Chemotherapy 60: 302-309, 2014

14. Nasrallah A, Saykali B, Al Dimassi S, Khoury N, Hanna S and El-Sibai M: Effect of StarD13 on colorectal cancer proliferation, motility and invasion. Oncol Rep 31: 505-515, 2014.

15. Perry JA and Maddox AS: Uncovering the secret life of Rho GTPases. Elife 8: e53276, 2019.

16. Li L, Zhao GD, Shi Z, Qi LL, Zhou LY and Fu ZX: The Ras/Raf/MEK/ERK signaling pathway and its role in the occurrence and development of HCC. Oncol Lett 12: 3045-3050, 2016

17. Shapiro P: Ras-MAP kinase signaling pathways and control of cell proliferation: Relevance to cancer therapy. Crit Rev Clin Lab Sci 39: 285-330, 2002.

18. Liu S, Moayeri M and Leppla SH: Anthrax lethal and edema toxins in anthrax pathogenesis. Trends Microbiol 22: 317-325, 2014.

19. Bachran $C$ and Leppla S: Tumor targeting and drug delivery by anthrax toxin. Toxins (Basel) 8: 197, 2016.

20. Agrawal A and Pulendran B: Anthrax lethal toxin: A weapon of multisystem destruction. Cell Mol Life Sci 61: 2859-2865, 2004.

21. Frankel AE, Koo HM, Leppla SH, Duesbery NS and Vande Woude GF: Novel protein targeted therapy of metastatic melanoma. Curr Pharm Des 9: 2060-2066, 2003.

22. Kassab E, Darwish M, Timsah Z, Liu S, Leppla SH, Frankel AE and Abi-Habib RJ: Cytotoxicity of anthrax lethal toxin to human acute myeloid leukemia cells is nonapoptotic and dependent on extracellular signal-regulated kinase $1 / 2$ activity. Transl Oncol 6 : 25-32, 2013

23. Koo HM, VanBrocklin M, McWilliams MJ, Leppla SH, Duesbery NS and Vande Woude GF: Apoptosis and melanogenesis in human melanoma cells induced by anthrax lethal factor inactivation of mitogen-activated protein kinase kinase. Proc Natl Acad Sci USA 99: 3052-3057, 2002.

24. Abi-Habib RJ, Singh R, Liu S, Bugge TH, Leppla SH and Frankel AE: A urokinase-activated recombinant anthrax toxin is selectively cytotoxic to many human tumor cell types. Mol Cancer Ther 5: 2556-2562, 2006.

25. Abi-Habib RJ, Urieto JO, Liu S, Leppla SH, Duesbery NS and Frankel AE: BRAF status and mitogen-activated protein/extracellular signal-regulated kinase kinase $1 / 2$ activity indicate sensitivity of melanoma cells to anthrax lethal toxin. Mol Cancer Ther 4: 1303-1310, 2005.

26. Duesbery NS, Resau J, Webb CP, Koochekpour S, Koo HM, Leppla SH and Vande Woude GF: Suppression of ras-mediated transformation and inhibition of tumor growth and angiogenesis by anthrax lethal factor, a proteolytic inhibitor of multiple MEK pathways. Proc Natl Acad Sci USA 98: 4089-4094, 2001.

27. Alfano RW, Leppla SH, Liu S, Bugge TH, Herlyn M, Smalley KS, Bromberg-White JL, Duesbery NS and Frankel AE: Cytotoxicity of the matrix metalloproteinase-activated anthrax lethal toxin is dependent on gelatinase expression and B-RAF status in human melanoma cells. Mol Cancer Ther 7: 1218-1226, 2008.

28. Al-Dimassi S, Salloum G, Saykali B, Khoury O, Liu S, Leppla SH, Abi-Habib R and El-Sibai M: Targeting the MAP kinase pathway in astrocytoma cells using a recombinant anthrax lethal toxin as a way to inhibit cell motility and invasion. Int J Oncol 48: 1913-1920, 2016.

29. Khalil BD, Hanna S, Saykali BA, El-Sitt S, Nasrallah A, Marston D, El-Sabban M, Hahn KM, Symons M and El-Sibai M: The regulation of RhoA at focal adhesions by StarD13 is important for astrocytoma cell motility. Exp Cell Res 321: 109-122, 2014.

30. Al Haddad M, El-Rif R, Hanna S, Jaafar L, Dennaoui R, Abdellatef S, Miskolci V, Cox D, Hodgson L and El-Sibai M Differential regulation of rho GTPases during lung adenocarcinoma migration and invasion reveals a novel role of the tumor suppressor StarD13 in invadopodia regulation. Cell Commun Signal 18: 144, 2020.
31. Jin $\mathrm{X}$ and $\mathrm{Mu} \mathrm{P}$ : Targeting breast cancer metastasis. Breast Cancer (Auckl) 9 (Suppl 1): S23-S34, 2015.

32. Shebaby WN, Mroueh M, Bodman-Smith K, Mansour A, Taleb RI, Daher CF and El-Sibai M: Daucus carota pentane-based fractions arrest the cell cycle and increase apoptosis in MDA-MB-231 breast cancer cells. BMC Complement Altern Med 14: 387, 2014

33. Yang SH, Sharrocks AD and Whitmarsh AJ: MAP kinase signalling cascades and transcriptional regulation. Gene 513: 1-13, 2013.

34. Tawil M, Bekdash A, Mroueh M, Daher CF and Abi-Habib RJ: Wild carrot oil extract is selectively cytotoxic to human acute myeloid leukemia cells. Asian Pac J Cancer Prev 16: 761-767, 2015.

35. Bekdash A, Darwish M, Timsah Z, Kassab E, Ghanem H, Najjar V, Ghosn M, Nasser S, El-Hajj H, Bazerbachi A, et al: Phospho-MEK1/2 and uPAR expression determine sensitivity of AML blasts to a urokinase-activated anthrax lethal toxin (PrAgU2/LF). Transl Oncol 8: 347-357, 2015.

36. Duesbery NS, Webb CP, Leppla SH, Gordon VM, Klimpel KR, Copeland TD, Ahn NG, Oskarsson MK, Fukasawa K, Paull KD and Vande Woude GF: Proteolytic inactivation of MAP-kinase-kinase by anthrax lethal factor. Science 280: 734-737, 1998

37. During RL, Li W, Hao B, Koenig JM, Stephens DS, Quinn CP and Southwick FS: Anthrax lethal toxin paralyzes neutrophil actin-based motility. J Infect Dis 192: 837-845, 2005.

38. Hernández SE, Settleman J and Koleske AJ: Adhesion-dependent regulation of p190RhoGAP in the developing brain by the Abl-related gene tyrosine kinase. Curr Biol 14: 691-696, 2004.

39. Hanna S, Khalil B, Nasrallah A, Saykali BA, Sobh R, Nasser S and El-Sibai M: StarD13 is a tumor suppressor in breast cancer that regulates cell motility and invasion. Int J Oncol 44: 1499-1511, 2014

40. Al-Koussa H, Al-Haddad M, Abi-Habib R and El-Sibai M: Human recombinant arginase I [HuArgI (Co)-PEG5000]-induced arginine depletion inhibits colorectal cancer cell migration and invasion. Int J Mol Sci 20: 6018, 2019.

41. El-Sibai M, Pertz O, Pang H, Yip SC, Lorenz M, Symons M, Condeelis JS, Hahn KM and Backer JM: RhoA/ROCK-mediated switching between Cdc42- and Rac1-dependent protrusion in MTLn3 carcinoma cells. Exp Cell Res 314: 1540-1552, 2008.

42. Zhou X and Zheng Y: Cell type-specific signaling function of RhoA GTPase: Lessons from mouse gene targeting. J Biol Chem 288: 36179-36188, 2013.

43. Sadok A and Marshall CJ: Rho GTPases: Masters of cell migration. Small GTPases 5: e29710, 2014.

44. Sakurai-Yageta M, Recchi C, Le Dez G, Sibarita J-B, Daviet L, Camonis J, D'Souza-Schorey C and Chavrier P: The interaction of IQGAP1 with the exocyst complex is required for tumor cell invasion downstream of Cdc42 and RhoA. J Cell Biol 181: 985-998, 2008.

45. National Institutes of Health (US): Understanding Cancer. NIH Curriculum Supplement Series [Internet]. National Institutes of Health (US), 2007 [cited 2020 Apr 10]. Available from: https://www.ncbi.nlm.nih.gov/books/NBK20362/

46. Faltas B: Cornering metastases: Therapeutic targeting of circulating tumor cells and stem cells. Front Oncol 2: 68, 2012

47. Nicolas S, Abdellatef S, Haddad MA, Fakhoury I and El-Sibai M: Hypoxia and EGF stimulation regulate VEGF expression in human glioblastoma multiforme (GBM) Cells by differential regulation of the PI3K/Rho-GTPase and MAPK pathways. Cells 8: 1397, 2019. 